\title{
Potential studies on Knee Osteoarthritis Segmentation and Classification
}

\author{
T. Sivakumari* and R.Vani \\ Department of Electronics and Communication Engineering, SRM Institute of \\ Science and Technology, Ramapuram, Chennai, India \\ Corresponding author email: st6876@srmist.edu.in
}

\begin{abstract}
In recent days automatic grading of Knee Osteoarthritis (KOA) is mainly helping to diagnose the severity of the disease. This illness is now diagnosed by a clinical examination and radiographic evaluation. However, these diagnostic tools have low sensitivity and specificity. Several methods have been developed that can automatically identify the KL grade from the radiographs. The KellgrenLawrence (KL) grading system is the golden standard that uses five categories to assess the severity of osteoarthritis. Many researchers have been developed models and evaluated on publically available dataset like Osteoarthritis Initiative dataset (OAI), Multicenter Osteoarthritis Study (MOST) dataset, KOACAD (OAI derived dataset). Data must be considered an important thing, since it is one of the most valuable assets in the healthcare area. Several data sources were used as inputs in KOA study, resulting in strong multidimensional training and testing data sets. To extract meaningful information from accessible data, a variety of feature selection methods were utilized. The segmentation algorithms such as canny edge detector, Graph cut algorithm, PCA and GLCM were used to extract the features or to reduce the space dimensionality. In an X-ray based investigations, Machine Learning models such as SVMs were most commonly chosen to drive the decision-making process. This paper discusses all the ideas on automatic grading of KOA published by each researcher.
\end{abstract}

KEY WORDS: AUTOMATIC GRADING, CONVOLUTION NEURAL NETWORK, CLASSIFICATION, KNEE OSTEOARTHRITIS, MACHINE LEARNING, SEGMENTATION.

\section{INTRODUCTION}

Arthritis is an inflammatory condition that affects one or more joints. Arthritis may be classified into over a hundred distinct kinds. Osteoarthritis (OA) and Rheumatoid arthritis (RA) are the two most prevalent kinds. The most prevalent musculoskeletal condition is osteoarthritis, commonly referred to as Wear and Tear arthritis or Degenerative Joint Disease. This disease generally influences the elderly people. Joint space narrowing (JSN), the development of osteophytes, and sclerosis are the main clinical

Biosc Biotech Res Comm P-ISSN: 0974-6455 E-ISSN: 2321-4007

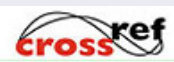

Identifiers and Pagination

Year: 2021 Vol: 14 No (7) Special Issue

Pages: 449- 456

This is an open access article under Creative

Commons License Attribn 4.0 Intl (CC-BY).

DOI: $h t t p: / / d x . d o i . o r g / 10.21786 / b b r c / 14.7 .94$ characteristics of KOA (Antony et al., 2017; Górriz et al., 2019; Kondal et al., 2020).

There is a tissue called cartilage which connects the bones and it cushions the ends of the bones to provide the frictionless joint motion. If the cartilage is damaged or unhealthy, the bones are rubs each other which causes pain, swelling and stiffness. The space between the bones narrows in KOA-affected knees, which is termed as Joint Space Narrowing (JSN). The common risk factors associated with osteoarthritis are Obesity, bone density, trauma, gender, lack of exercise, genetic predisposition (Wahyuningrum et al., 2019; Kondal et al., 2020). Early diagnosis is the only option to reduce its impact and lead the healthy life, because the joint replacement surgery can be done only at early stage of OA. According to the survey, there were 303 million cases of hip and Knee osteoarthritis worldwide as of 2017. The purpose of this article was to offer a quick overview of research work done by a number of researchers on the identification and classification of KOA and its severity 
using simple radiographs (Wang et al., 2019; Kondal et al., 2020).

Figure 1: Healthy and KOA affected Knee image (Gornale et al., 2019)

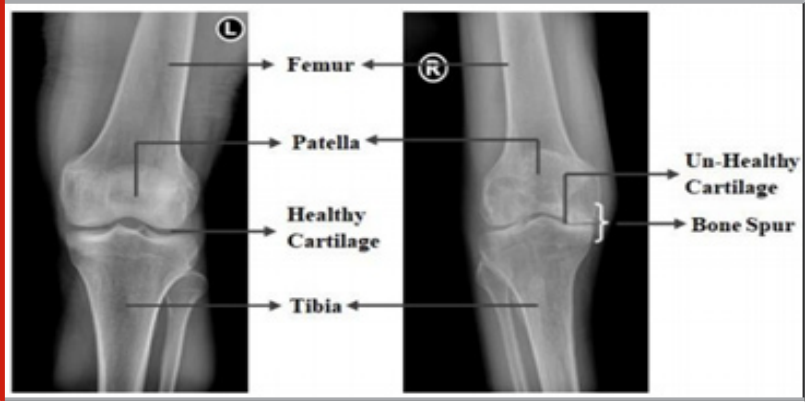

Figure 2: KL Grade Scale

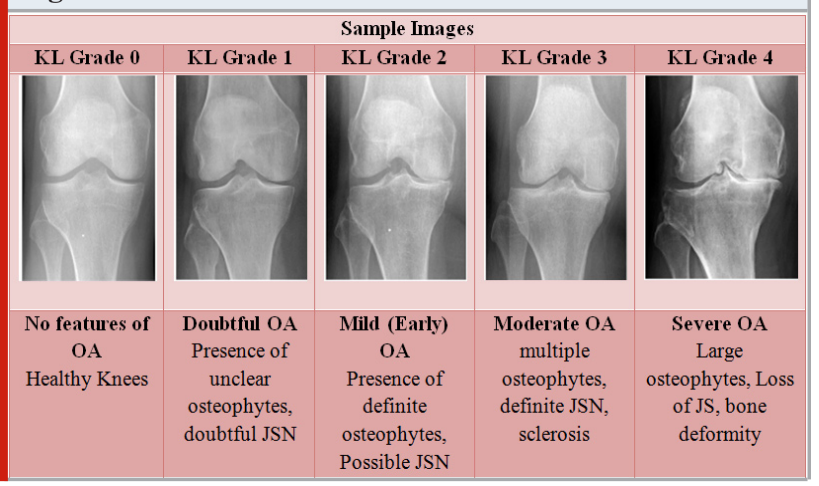

Table 1. Osteoarthritis Cartilage Histopathology Assessment System

\begin{tabular}{|l|c|}
\hline Grade & Explanation \\
\hline Grade-0 & surface intact, cartilage intact \\
\hline Grade-1 & $\begin{array}{c}\text { Uneven but intact Possible features: } \\
\text { superficial fibrillation, } \\
\text { cell death and proliferation. }\end{array}$ \\
\hline Grade-2 & surface discontinuity \\
\hline Grade-3 & vertical fissures \\
\hline Grade-4 & Erosion \\
\hline Grade-5 & Denudation \\
\hline
\end{tabular}

Table 2. Stage Assessment OA Cartilage Histopathology

\begin{tabular}{|l|c|}
\hline Stages & \% Involvement (Surface) \\
\hline Stage-0 & No OA activity seen \\
\hline Stage-1 & Less than $10 \%$ \\
\hline Stage-2 & Between 10 to $25 \%$ \\
\hline Stage-3 & Between 25 to $50 \%$ \\
\hline Stage- 4 & $4>50 \%$ \\
\hline
\end{tabular}

The medical imaging methods such as MRI, CT scan, Ultrasound, and plain radiography (X-rays) are used to detect the early signs of OA. Among these techniques, $\mathrm{X}$-rays is the cheap, readily available and this will be less hazardous technique. Clinicians generally analyze the plain radiographic images of $\mathrm{OA} / \mathrm{Non} \mathrm{OA}$ knees to grade the severity of OA with the help of Kellgren-Lawrence (KL) grades. The normal and affected knee cartilage image is shown in the above Figure 1 (Pedoia et al., 2019).

KL Grading scale: KL grades have been accepted globally for measuring the severity of knee Osteoarthritis. This grading system has five (0-4) stages shown in figure 2. Grade 0 represents the healthy knees and subsequent grades (1-4) represent the increasing severity of OA (Roemer et al., 2018). OARSI Grading System: An Osteoarthritis cartilage histopathology assessment system (OARSI system) is first introduced by the Osteoarthritis Research Society International (OARSI) in the year of 2006. This system composed of a grading and Staging component. This method is made up of two parts: Grading and Staging. The capacity to distinguish between early and moderate OA is the system's key feature. OARSI grades and stages are listed in table $1 \& 2$.

Available Datasets for KOA: Researchers have worked on a variety of data sets, either publicly available or gathered by own. The well-known publicly available data sets are OAI, MOST, BLSA, and OAI derived data set (KOACAD). Most of the researcher has used OAI data set. Some researchers used more than one data set for their work. According to the requirement, few authors collect the data with their own interest. Table 3 shows most commonly used dataset and their description (Dey et al., 2018; Kondal et al., 2020).

Machine Learning in Knee Osteoarthritis: The goal of this section is to give an overview of Machine Learning (ML) in medical applications, with a focus on Knee Osteoarthritis. Machine learning approach has been widely applied in a variety of applications, including medical imaging, segmentation, classification and image identification (Raj et al., 2018; Juras et al., 2020).

Machine Learning is a field of Artificial Intelligence that allows computers to learn from their experiences and solve problems. The mathematical model must first be constructed, after which it must be trained to generate the results. Machine learning models are trained through the use of training data, which is subsequently fine-tuned using optimization approach to provide accurate predictions. The tuned models are to be able to generalize their expertise and bring the correct prediction for new data. Machine Learning provides intelligent solutions in medical applications, improving clinical diagnostic accuracy. There are various machine learning algorithms available such as Support vector machines, $\mathrm{kNN}$, Logistic regression and so. The researcher can be selecting the algorithm with respect to the nature of problem (Saini et al., 2021; Revathy et al., 2021).

The machine learning system has two parts (i) Training Part (ii) Testing Part shown in figure 3. Initially data to be used for training is undergoes preprocessing such as data cleaning, data integration, data transformation including 
discretization and normalization. Next step is Feature extraction which is used to identify the relevant feature and subsequently mathematical model will be applied in training part Gan et al., (2021). The feature extraction portion and the pre-processing unit are adjusted via a feedback loop, which improves the model's performance. During testing part the models are taking proper decision based on the feature present in each sample.

\begin{tabular}{|c|c|c|}
\hline Dataset & Number of Participants & Description \\
\hline OAI-Osteoarthritis Initiative & 4796 & $\begin{array}{l}\text { i)Sponsored by the } \\
\text { National Institutes of Health } \\
\text { ii) Multi-centre } \\
\text { iii) Ten-year observational } \\
\text { study of men and women }\end{array}$ \\
\hline MOST-Multicenter Osteoarthritis Study & 3026 & $\begin{array}{l}\text { i) Sponsored by the National Institutes of } \\
\text { Health / National Institute on Aging } \\
\text { ii) Lateral knee assessment for } 84 \text { months. }\end{array}$ \\
\hline $\begin{array}{l}\text { BLSA-Baltimore Longitudinal } \\
\text { Study of Aging }\end{array}$ & More than 3200 & $\begin{array}{l}\text { i) It began in } 1958 \\
\text { ii) Longitudinal normative aging study } \\
\text { iii) Radiographs were obtained in all } \\
\text { participants, irrespective of symptoms } \\
\text { or functional limitations. }\end{array}$ \\
\hline
\end{tabular}

Figure 3: Block of Machine Learning System (Tack et al., 2021)

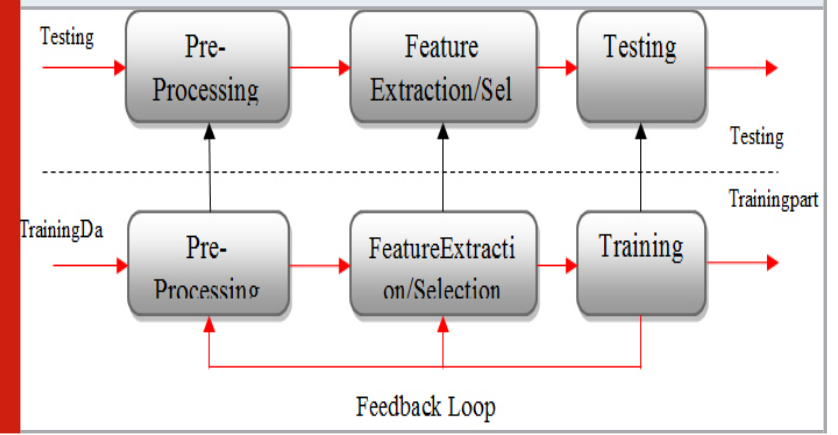

Segmentation: Whenever the patient comes to the orthopedic he/she is advised to take MRI or X-ray for further evaluation. An image contains more information and this information can be extracted automatically by the process called segmentation. This process is a fundamental step in image analysis (Wang et al., 2021; Yifan et al., 2021). The manual evaluation may take some time to reach conclusion and it is not error-free. Generally in the segmentation process, a digital image can be divided into multiple segments which gives a better understanding of the further processing. Many segmentation methods have been developed analyzing medical data of the patients such as MRI (Magnetic Resonance Imaging), X-Rays, CT (Computerized Tomography) scans, ECG (Electro Cardio Gram), and are stored in DICOM format (Tiulpin et al., 2019; Felfeliyan et al., 2021).

There are three types of classical segmentation methods. The first one is Manual segmentation which is necessary to precisely delineate the boundaries of damaged cartilage by placing seeds over specific anatomic regions. Despite this, the treatments are notorious for being time-consuming. It fully depends on the doctor's experience and knowledge of anatomy. The second method is automated segmentation and is used to segment the cartilage automatically (Rosenberger et al., 2006; Mahmood et al., 2015; Dalia et al., 2021). Some of the methods are active shape model, watershed and $\mathrm{kNN}$ classification. Another method is interactive segmentation; it combines features from both manual and automated segmentation methods such as graph cuts and random walks. The various segmentation methods have been reviewed for detection of knee osteoarthritis in early states. The simple method and robust method is nobel edge detection that highlights the region of high spatial frequency (Mahmood et. al., 2015; Gornale et al., 2019; Von et al., 2021; Sarvamangala et al., 2021).

There are many algorithms for gray scale image segmentation. But the threshold segmentation algorithm is used commonly because of its simplicity and efficiency. An OTSU threshold segmentation technique has been applied to ROI of joint space area of the knee to get the clear joint gap but its computation time is high when the number of threshold increases. Table. 4 gives the comparative study of various algorithms have been used for segmentation process (Chan et al., 2020; Palacios and Laura, 2021; Chai et al., 2021). Classification: The research on Knee OA can be carried out in two ways. One is automatically classifying the images into KOA and non-KOA cases. Another one is classification of KOA severity by quantifying pathological features. The most common pathological features of Knee OA are osteophytes formation, joint space narrowing (JSN), and subchondral sclerosis. All these pathological features are playing a major role in identifying the grading of $\mathrm{KOA}$ like KL and OARSI grading system. The researchers have been classified the KOA severity by quantifying any one pathological features and some researchers have used composite grading systems (Kokkotis et al., 2020). 
Table 4. Comparative study of various segmentation techniques used in KOA

\begin{tabular}{|c|c|c|c|}
\hline Ref & $\begin{array}{c}\text { Number of } \\
\text { Images Used }\end{array}$ & Algorithm & Result \\
\hline $\begin{array}{l}\text { Anifah } \\
\text { et al., } \\
2013\end{array}$ & - & $\begin{array}{l}\text { 3D Statistical } \\
\text { Shape models } \\
(\mathrm{SSM}) \text { as well as } \\
\text { 2D and } 3 \mathrm{D} \mathrm{CNN}\end{array}$ & 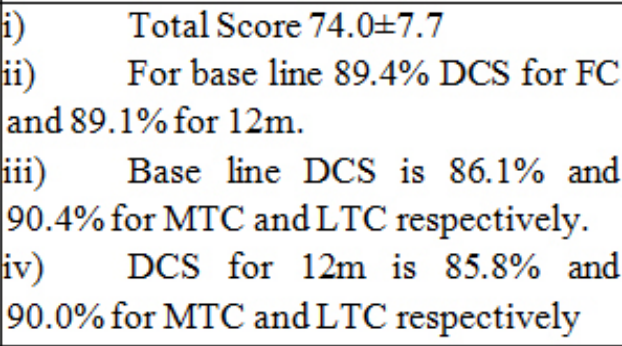 \\
\hline $\begin{array}{c}\text { Anifah } \\
\text { et al., } \\
2018\end{array}$ & $\begin{array}{lr}532 & X \text {-ray } \\
\text { Images: } 301- \\
\text { female and } \\
231-\text { male }\end{array}$ & $\begin{array}{l}\text { Otsu's } \\
\text { segmentation, } \\
\text { KNN, Texture } \\
\text { based } \\
\text { segmentation }\end{array}$ & $\begin{array}{l}\text { Obtained accuracy of } 94.92 \%, 91.16 \% \text {, } \\
96.80 \% \text {, and } 97.55 \% \text { for texture } \\
\text { method, Sobel method, Otsu's method, } \\
\text { and Prewitt method respectively. }\end{array}$ \\
\hline $\begin{array}{c}\text { Bien et } \\
\text { al., } 2018\end{array}$ & $\begin{array}{l}\text { OAI: } 748, \\
\text { Dataset } \\
\text { 161(Own } \\
\text { dataset), } \\
\text { Dataset B: } 209 \\
\text { (Own Dataset) }\end{array}$ & $\begin{array}{l}\text { Hourglass } \\
\text { Network }\end{array}$ & Precision $93.48 \pm 0.44$ \\
\hline $\begin{array}{c}\text { Dey et } \\
\text { al., } 2008\end{array}$ & 10 & $\begin{array}{l}\text { Flexible seeds } \\
\text { labelling method }\end{array}$ & $\begin{array}{l}\text { For obsever } 1, \text { the average Dice } \\
\text { coefficient- } 0.80 \pm 0.060, \text { sensitivity } \\
0.86 \pm 0.044 \text { and specificity } \\
0.994 \pm 0.0019 \text {. } \\
\text { For observer } 2, \text { the average Dice } \\
\text { coefficient- } 0.82 \pm 0.043 \text {, sensitivity } \\
0.85 \pm 0.049 \text { and specificity } 0.995 \pm \\
0.0010 .\end{array}$ \\
\hline Górriz eț & $\begin{array}{l}\text { Dataset A: } 88 \\
\text { Dataset B: } 600 \\
\text { Dataset C: } 184 \\
\text { Dataset D: } 184 \\
\text { Dataset E: } 184\end{array}$ & $\begin{array}{l}\text { 3D } \\
\text { Neural Network }\end{array}$ & $\begin{array}{lll}\text { Accuracy: } & \text { Medial tibial cartilage- } \\
88.02 \pm 4.62 & \text { lateral tibial cartilage - } \\
91.27 \pm 2.33 & & \end{array}$ \\
\hline $\begin{array}{c}\text { Kokkotis } \\
\text { et al., } \\
2020\end{array}$ & 4130 images & $\begin{array}{l}\text { Single } \\
\text { Detector }\end{array}$ & $94.03 \%$ of images having $\mathrm{J}>0.75$ \\
\hline
\end{tabular}

Gornale et al., (2016) have considered the following features: Texture features, Haralick, First four movements, statistical feature set, and region properties. These features were classified using Random Forest Classifier. In this work, the miss classified rate is little high in individual feature set whereas the proposed algorithm provides a better result for the combined feature sets. One of the procedure of examine the knee osteoarthritis is analyzing the joint space width (Kondal et al., (2020). The multidisciplinary data from OAI were used in Ntakolia et al., (2021) to predict the progression of JSN where the proposed methodology employs clustering process, Feature selection process and decision making process. They concluded that LR model produced significantly good accuracy while combining data of both legs. Recent research works have been focused particularly on patellofemoral Osteoarthritis Bayramoglu et al., (2021).

The automatic JSW measurement is more accurate that manual measurement method. For the comparison purpose an author has done the manual measurement by using ruler to join the outermost of each femur and tibia. As a result, the lateral Joint space width is narrower that medial joint space width where as in automatic method the medial 
JSW is narrower that the lateral JSW. In table 5 it has been analyzed that the various classification techniques such as
SVM, Random Forest Classifier and various CNN networks have been used by the researchers for classification of knee Osteoarthritis (Sugiyanto et al., 2020).

Table 5. Comparative survey of various classification techniques used in KOA

\begin{tabular}{|c|c|c|c|c|c|c|}
\hline Reference & $\begin{array}{c}\text { Yea } \\
\text { r }\end{array}$ & $\begin{array}{c}\text { Datas } \\
\text { et }\end{array}$ & Data & $\begin{array}{l}\text { Number of } \\
\text { Images Used }\end{array}$ & Algorithm & Result \\
\hline $\begin{array}{l}\text { Yang et al., } \\
\quad(2021)\end{array}$ & 2017 & $\begin{array}{l}\text { Own } \\
\text { dataset }\end{array}$ & $\begin{array}{l}\mathrm{X}- \\
\text { ray }\end{array}$ & 616 & $\begin{array}{l}\text { Multiclass } \\
\text { SVM }\end{array}$ & $\begin{array}{l}\text { Accuracy for } \mathrm{KL} \\
\text { Grade-0: } 97.96 \% \text {, } \\
\text { Grade-1:92.85\%, } \\
\text { Grade-2:86.20\% } \\
\text { Grade-3\&4: } 100 \%\end{array}$ \\
\hline $\begin{array}{l}\text { Gornale et } \\
\text { a., } 2021\end{array}$ & 2016 & $\begin{array}{l}\text { Own } \\
\text { dataset }\end{array}$ & $\begin{array}{l}\mathrm{X}- \\
\text { ray }\end{array}$ & $\mid \begin{array}{lr}128 & \text { images: } 62 \\
\text { of } & \text { normal } \\
\text { condition } & \text { and } \\
\text { of } & 66\end{array}$ & $\begin{array}{l}\text { Random } \\
\text { Forest } \\
\text { Classifier }\end{array}$ & $\begin{array}{l}\text { Accuracy of } \\
87.92 \%\end{array}$ \\
\hline $\begin{array}{l}\text { Oei et al., } \\
2021\end{array}$ & 2017 & $\begin{array}{l}\text { Own } \\
\text { dataset }\end{array}$ & MRI & $\begin{array}{l}\text { There are } 213 \\
\text { images in total: } \\
147 \text { for training } \\
\text { and } 66 \text { for } \\
\text { testing. }\end{array}$ & $\begin{array}{l}\text { SVM } \\
\text { classifier }\end{array}$ & $\begin{array}{l}95.45 \% \text { for } \text { SVM } \\
\text { with RBF kernel, } \\
87.8 \% \text { for SVM } \\
\text { with linear kernel. }\end{array}$ \\
\hline \multirow[t]{2}{*}{$\begin{array}{l}\text { Edwin et al., } \\
\quad 2021\end{array}$} & 2018 & $\begin{array}{l}\text { Own } \\
\text { dataset }\end{array}$ & MRI & \begin{tabular}{|l|}
$1370 \quad$ knee \\
images
\end{tabular} & $\begin{array}{l}\text { CNN- } \\
\text { MRNet, }\end{array}$ & $\begin{array}{l}\text { AUC } \\
\text { values:Detecting }\end{array}$ \\
\hline & & & & & & $\begin{array}{l}\text { abnormalities- } \\
0.937, \text { ACL tears- } \\
0.965, \quad \text { Meniscal } \\
\text { tears- } 0.847 .\end{array}$ \\
\hline $\begin{array}{l}\text { Ebrahimkha } \\
\text { ni et al } 2021\end{array}$ & 2019 & $\mathrm{OAI}$ & MRI & 4384 subjects & $\begin{array}{l}\text { CNN- } \\
\text { DenseNet }\end{array}$ & $\begin{array}{l}\text { For RF model, } \\
\text { Sensitivity- } \\
67.01 \% \text {, } \\
\text { Specificity- } 71.79 \% \\
\text { For DenseNet, } \\
\text { Sensitivity- } 76.99 \% \text {, } \\
\text { Specificity- } 77.94 \%\end{array}$ \\
\hline $\begin{array}{l}\text { Cicuttini, } \\
2021\end{array}$ & 2016 & $\begin{array}{l}\text { Own } \\
\text { dataset }\end{array}$ & MRI & 15 subjects & \begin{tabular}{|l|} 
SVM \\
Classifier
\end{tabular} & $\begin{array}{l}\text { Accuracy } 86.66 \% \\
\text { Specificity } 100 \% \\
\text { Sensitivity } 75 \%\end{array}$ \\
\hline $\begin{array}{c}\text { Wahyuningr } \\
\text { um et al., } \\
2021\end{array}$ & 2013 & OAI & $\begin{array}{l}\mathrm{X}- \\
\text { ray }\end{array}$ & $\begin{array}{l}303 \text { unimpaired } \\
\text { images }\end{array}$ & $\begin{array}{l}\text { SOM- Self } \\
\text { Organizing } \\
\text { Maps }\end{array}$ & $\begin{array}{l}\text { Accuracy for } \mathrm{KL} \\
\text { Grade-0: } 93.8 \% \text {, } \\
\text { Grade-1:70\%, } \\
\text { Grade-2:4\% } \\
\text { Grade-3: } 10 \% \text { and } \\
\text { Grade- } 4: 88.9 \%\end{array}$ \\
\hline $\begin{array}{l}\text { Tack., et al., } \\
2021\end{array}$ & 2018 & OAI & $\begin{array}{l}\mathrm{X}- \\
\text { ray }\end{array}$ & $\begin{array}{l}303 \text { unimpaired } \\
\text { images }\end{array}$ & SOM & $\begin{array}{l}\text { Accuracy for } \mathrm{KL} \\
\text { Grade-0: } 36.21 \% \\
\text { Grade-1: } 40.52 \% \\
\text { Grade- } 2: 15.52 \% \\
\text { Grade- } 3: 25.86 \% \\
\text { Not able to classify } \\
\text { KL Grade } 4\end{array}$ \\
\hline $\begin{array}{l}\text { Wang et al., } \\
2021\end{array}$ & 2020 & $\begin{array}{l}\text { OAI } \\
\text { and } \\
\text { MOST }\end{array}$ & $\begin{array}{l}\mathrm{X}- \\
\text { ray }\end{array}$ & $\begin{array}{l}19704 \text { knees } \\
\text { from the OAI } \\
\text { dataset were used } \\
\text { as a training set. } \\
11743 \text { knees } \\
\text { from the MOST } \\
\text { dataset were used } \\
\text { in the testing. }\end{array}$ & $\begin{array}{l}\text { Transfer } \\
\text { Learning } \\
\text { from Image } \\
\text { Net }\end{array}$ & $\begin{array}{l}\text { Cohen's } r \text { Kappa } \\
\text { coefficient for KL } \\
\text { is } 0.82 \text { and } 0.79 \text {, } \\
0.84 \text { for femoral } \\
\text { osteophytes (lateral } \\
\text { and medial } \\
\text { compartment), for } \\
\text { tibial osteophytes } \\
0.94 \text { and } 0.83 \\
\text { (lateral and medial } \\
\text { compartment). } 0.84 \\
\text { and } 0.90 \text { for Joint }\end{array}$ \\
\hline & & & & & & Space Narrowing. \\
\hline $\begin{array}{l}\text { Dalia et al., } \\
2021\end{array}$ & 2021 & OAI & $\begin{array}{l}\mathrm{X}- \\
\text { rays }\end{array}$ & 4130 images & DenseNets & $\begin{array}{l}\text { Average Multi class } \\
\text { accuracy is } 71.08 \%\end{array}$ \\
\hline $\begin{array}{l}\text { Yong et al., } \\
2021\end{array}$ & 2020 & \begin{tabular}{|l} 
OAI, \\
data set \\
from \\
private \\
hospital \\
in \\
India. \\
\end{tabular} & $\begin{array}{l}\mathrm{X}- \\
\text { rays }\end{array}$ & $\begin{array}{lr}4447 & \text { knee } \\
\text { images from } \\
\text { OAI and } 1043 \\
\text { from } \\
\text { hospital. }\end{array}$ & CNN & $\begin{array}{l}\text { The mean absolute } \\
\text { error from } 1.09 \text { to } \\
0.28\end{array}$ \\
\hline
\end{tabular}




\section{CONCLUSION}

The several machine learning approaches for KOA diagnostic and prediction have been discussed in above literature review. The development of disease can be avoided by diagnosing it earlier and can be treated appropriately. Data must be considered an important thing, since it is one of the most valuable assets in the healthcare area. Several data sources were used as inputs in KOA study, resulting in strong multidimensional training and testing data sets.

To extract meaningful information from accessible data, a variety of feature selection methods were utilized. The segmentation algorithms such as canny edge detector, Graph cut algorithm, PCA and GLCM were used to extract the features or to reduce the space dimensionality. In an $\mathrm{X}$-ray based investigations, Machine Learning models such as SVMs were most commonly chosen to drive the decision-making process. In the future, the research work can be extended to formulate more efficient segmentation and classification algorithms to automatic grading of KOA where Deep learning approach such as VGG-19, VGG16,DenseNet, ResNet-34, and LSTM will be the best choice because of its automatic methodology though it requires large data, high power GPU and better performance graphics processing units. Since it will be useful for earlier diagnosis and it might be possible to slow down its progression.

\section{REFERENCES}

Ambellan, F., Tack, A., Ehlke, M. and Zachow, S., (2019). Automated segmentation of knee bone and cartilage combining statistical shape knowledge and convolutional neural networks: Data from the Osteoarthritis Initiative. Medical image analysis, 52, pp.109-118.

Anifah, L., Purnama, I.K.E., Hariadi, M. and Purnomo, M.H., (2013). Osteoarthritis classification using selforganizing map based on gabor kernel and contrast-limited adaptive histogram equalization. The open biomedical engineering journal, 7, p.18.

Anifah, L., Purnomo, M.H., Mengko, T.L.R. and Purnama, I.K.E., (2018). February. Osteoarthritis severity determination using self organizingmap based Gabor kernel. In IOP Conference Series: Materials Science and Engineering (Vol. 306, No. 1, p. 012071). IOP Publishing.

Bayramoglu, N., Nieminen, M.T. and Saarakkala, S., (2021). Machine Learning Based Texture Analysis of Patella from X-Rays for Detecting Patellofemoral Osteoarthritis. arXiv preprint arXiv:2106.01700.

Bien, N., Rajpurkar, P., Ball, R.L., Irvin, J., Park, A., Jones, E., Bereket, M., Patel, B.N., Yeom, K.W., Shpanskaya, K. and Halabi, S., (2018). Deep-learning-assisted diagnosis for knee magnetic resonance imaging: development and retrospective validation of MRNet. PLoS medicine, 15(11), p.e1002699.

Chai, R., (2021). Otsu's Image Segmentation Algorithm with Memory-Based Fruit Fly Optimization Algorithm. Complexity.

Chan, S., Dittakan, K. and El Salhi, S., (2020).
Osteoarthritis detection by applying quadtree analysis to human joint knee X-ray imagery. International Journal of Computers and Applications, pp.1-8.

Dalia, Yuvraj, Adikar Bharath, Veena Mayya, and S. Sowmya Kamath. (2021). DeepOA: Clinical Decision Support System for Early Detection and Severity Grading of Knee Osteoarthritis. In 2021 5th International Conference on Computer, Communication and Signal Processing (ICCCSP), pp. 250-255.

Dey, R.; Lu, Z.; Hong, Y. (2008). Diagnostic classification of lung nodules using 3D neural networks. In Proceedings of the 2018 IEEE 15th International Symposium on Biomedical Imaging (ISBI), Washington, DC, USA, 4-7 April 2018; IEEE: Piscataway, NJ, USA, 2018; pp. 774-778

Ebrahimkhani, Somayeh, Anuja Dharmaratne, Mohamed Hisham Jaward, Yuanyuan Wang, and Flavia M. Cicuttini (2021). Automated Segmentation of Knee Articular Cartilage: Joint Deep and Hand-Crafted LearningBased Framework Using Diffeomorphic Mapping. Neurocomputing.

Edwin Oei, HG, Tijmen A. van Zadelhoff, Susanne M. Eijgenraam, Stefan Klein, Jukka Hirvasniemi, and Rianne A. van der Heijden (2021). 3D MRI in Osteoarthritis. In Seminars in Musculoskeletal Radiology, vol. 25, no. 03, pp. 468-479. Thieme Medical Publishers, Inc., 2021

Felfeliyan, Banafshe, Abhilash Hareendranathan, Gregor Kuntze, Jacob L. Jaremko, and Janet L. Ronsky (2021). Improved-Mask R-CNN: Towards an Accurate Generic MSK MRI instance segmentation platform (Data from the Osteoarthritis Initiative). arXiv preprint arXiv:2107.12889

Gan, Hong-Seng, Muhammad Hanif Ramlee, Asnida Abdul Wahab, Yeng-Seng Lee, and Akinobu Shimizu (2021). From classical to deep learning: review on cartilage and bone segmentation techniques in knee osteoarthritis research." Artificial Intelligence Review 54, no. 4: 2445 2494

Gornale, Shivanand S., Pooja U. Patravali, and Prakash S. Hiremath (2021). Identification of region of interest for assessment of knee osteoarthritis in radiographic images. International Journal of Medical Engineering and Informatics 13, no. 1: 64-74

Górriz, M.; Antony, J.; McGuinness, K.; Giró-i-Nieto, X.; O'Connor, N.E. (2019). Assessing Knee OA Severity with CNN attention-based end-to-end architectures. arXiv 2019, arXiv: 1908.08856

Gan, H.S., Sayuti, K.A., Harun, N.H. and Karim, A.H.A., (2016). Flexible non cartilage seeds for osteoarthritic magnetic resoance image of knee: data from the osteoarthritis initiative. In 2016 IEEE EMBS conference on biomedical engineering and sciences (IECBES) (pp. 748-751). IEEE.

Gornale, S.S., Patravali, P.U. and Manza, R.R., (2016). Detection of osteoarthritis using knee X-ray image analyses: a machine vision based approach. Int. J. Comput. Appl, 145(1), pp.0975-8887. 
Gornale, S.S., Patravali, P.U., Marathe, K.S. and Hiremath, P.S., (2017). Determination of osteoarthritis using histogram of oriented gradients and multiclass SVM. International Journal of Image, Graphics and Signal Processing, 9(12), p.41.

Gornale, S.S., Patravali, P.U., Uppin, A.M. and Hiremath, P.S., (2019). Study of segmentation techniques for assessment of osteoarthritis in knee X-ray images. International Journal of Image, Graphics and Signal Processing (IJIGSP), 11(2), pp.48-57.

Juras, V.; Chang, G.; Regatte, R.R. (2020). Current status of functional MRI of osteoarthritis for diagnosis and prognosis. Curr. Opin. Rheumatol, 32, 102.

Kokkotis, C., Moustakidis, S., Papageorgiou, E., Giakas, G. and Tsaopoulos, D.E., (2020). Machine learning in knee osteoarthritis: A review. Osteoarthritis and Cartilage Open, 2(3), p. 100069.

Kondal, S., Kulkarni, V., Gaikwad, A., Kharat, A. and Pant, A., (2020). Automatic Grading of Knee Osteoarthritis on the Kellgren-Lawrence Scale from Radiographs Using Convolutional Neural Networks. arXiv preprint arXiv:2004.08572.

Kubkaddi, S. and Ravikumar, K.M., (2017). Early detection of knee osteoarthritis using SVM classifier. IJSEAT, 5(3), pp.259-262.

Kumar, V.A. and Jayanthy, A.K., (2016). Classification of MRI images in 2D coronal view and measurement of articular cartilage thickness for early detection of knee osteoarthritis. In 2016 IEEE International Conference on Recent Trends in Electronics, Information \& Communication Technology (RTEICT) (pp. 19071911). IEEE.

Mahmood, N., Shah, A.S.A.D.U.L.L.A.H., Waqas, A., Abubakar, A.D.A.M.U., Kamran, S.H.A.F.I.A. and Zaidi, S.B., (2015). Image segmentation methods and edge detection: An application to knee joint articular cartilage edge detection. Journal of Theoretical and Applied Information Technology, 71(1), pp.87-96.

Mikhaylichenko, A. and Demyanenko, Y., (2020). Automatic grading of knee osteoarthritis from plain radiographs using densely connected convolutional networks. In International Conference on Analysis of Images, Social Networks and Texts (pp. 149-161). Springer, Cham.

Ntakolia, C., Kokkotis, C., Moustakidis, S. and Tsaopoulos, D., (2021). Prediction of Joint Space Narrowing Progression in Knee Osteoarthritis Patients. Diagnostics, 11(2), p.285.

Oei, Edwin HG, Tijmen A. van Zadelhoff, Susanne M. Eijgenraam, Stefan Klein, Jukka Hirvasniemi, and Rianne A. van der Heijden (2021). 3D MRI in Osteoarthritis. In Seminars in Musculoskeletal Radiology, vol. 25, no. 03, pp. 468-479. Thieme Medical Publishers, Inc.

Palacios Peral, Laura. (2021). Hip joint space analysis for osteoarthritis diagnosis.

Pedoia, V.; Norman, B.; Mehany, S.N.; Bucknor, M.D.; Link, T.M.; Majumdar, S. (2019). 3D convolutional neural networks for detection and severity staging of meniscus and PFJ cartilage morphological degenerative changes in osteoarthritis and anterior cruciate ligament subjects. J. Magn. Reson. Imaging 2019, 49, 400-410.

Pedoia, V., Lee, J., Norman, B., Link, T.M. and Majumdar, S., (2019). Diagnosing osteoarthritis from T2 maps using deep learning: an analysis of the entire Osteoarthritis Initiative baseline cohort. Osteoarthritis and cartilage, 27(7), pp.1002-1010.

Puri, S. and Singh, S., (2021). Image Segmentation Techniques: A Survey. International Journal of Engineering and Applied Physics, 1(2), pp.127-135.

Rosenberger, C., Chabrier, S., Laurent, H. and Emile, B., (2006). Unsupervised and supervised image segmentation evaluation. In Advances in image and video segmentation (pp. 365-393). IGI Global.

Raj, A.; Vishwanathan, S.; Ajani, B.; Krishnan, K.; Agarwal, H. (2018). Automatic knee cartilage segmentation using fully volumetric convolutional neural networks for evaluation of osteoarthritis. In Proceedings of the 2018 IEEE 15th International Symposium on Biomedical Imaging (ISBI 2018), Washington, DC, USA, 4-7 April 2018; IEEE: Piscataway, NJ, USA, pp. 851-854.

Revathy, B., M. Subramoniam, S. Poornapushpakala, and S. Barani. (2021). A Review on Investigation and Catagorization of Rheumatoid Arthritis and Osteoarthritis Using Image Processing Techniques. Annals of the Romanian Society for Cell Biology 25, no. 4: 22752290

Roemer, F.W.; Kwoh, C.K.; Hayashi, D.; Felson, D.T.; Guermazi, A. (2018). The role of radiography and MRI for eligibility assessment in DMOAD trials of knee OA. Nat. Rev. Rheumatol. 14, 372-380

Saini, Deepak, Trilok Chand, Devendra K. Chouhan, and Mahesh Prakash (2021). A comparative analysis of automatic classification and grading methods for knee osteoarthritis focussing on X-ray images. Biocybernetics and Biomedical Engineering.

Sarvamangala, D. R., and Raghavendra V. Kulkarni (2021). Grading of Knee Osteoarthritis Using Convolutional Neural Networks." Neural Processing Letters 1-25.

Shim, H., Chang, S., Tao, C., Wang, J.H., Kwoh, C.K. and Bae, K.T., (2009). Knee cartilage: efficient and reproducible segmentation on high-spatial-resolution MR images with the semiautomated graph-cut algorithm method. Radiology, 251(2), pp.548-556.

Sugiyanto, S., Fatimah, F., Budi, W.S., Suwondo, A. and Suyanto, H., (2021). Comparison of Joint Space Width Determinations in Grade I and II Knee Osteoarthritis Patients Using Manual and Automatic Measurements. Journal of Biomedical Physics and Engineering.

Tack, A., Mukhopadhyay, A. and Zachow, S., (2018). Knee menisci segmentation using convolutional neural networks: data from the osteoarthritis initiative. Osteoarthritis and cartilage, 26(5), pp.680-688.

Tack, Alexander, Felix Ambellan, and Stefan Zachow (2021). Towards novel osteoarthritis biomarkers: Multi- 
criteria evaluation of 46,996 segmented knee MRI data from the Osteoarthritis Initiative." PLOS ONE 16, no. 10: e0258855.

Tiulpin, A. and Saarakkala, S., (2020). Automatic grading of individual knee osteoarthritis features in plain radiographs using deep convolutional neural networks. Diagnostics, 10(11), p.932.

Tiulpin, A., Melekhov, I. and Saarakkala, S., (2019). Kneel: knee anatomical landmark localization using hourglass networks. In Proceedings of the IEEE/CVF International Conference on Computer Vision Workshops (pp. 0-0).

Tiulpin, A., Thevenot, J., Rahtu, E. and Saarakkala, S., (2017). A novel method for automatic localization of joint area on knee plain radiographs. In Scandinavian Conference on Image Analysis (pp. 290-301). Springer, Cham.

von Schacky, Claudio E., Nikolas J. Wilhelm, Valerie S. Schäfer, Yannik Leonhardt, Felix G. Gassert, Sarah C. Foreman, Florian T. Gassert et al. (2021). Multitask deep learning for segmentation and classification of primary bone tumors on radiographs. Radiology: 204531.

Wahyuningrum, R.T.; Anifah, L.; Purnama, I.K.E.;
Purnomo, M.H. (2019). A New Approach to Classify Knee Osteoarthritis Severity from Radiographic Images based on CNN-LSTM Method. In Proceedings of the 2019 IEEE 10th International Conference on Awareness Science and Technology (iCAST), Morioka, Japan, 23-25 October 2019; IEEE: Piscataway, NJ, USA, 2019; pp. 1-6

Wang, T.; Leung, K.; Cho, K.; Chang, G.; Deniz, C.M. Total Knee Replacement prediction using Structural MRIs and 3D Convolutional Neural Networks. In Proceedings of the International Conference on Medical Imaging with Deep Learning - Extended Abstract Track, London, UK, 8-10 July 2019.

Wang, Yifan, Zhaori Bi, Yuxue Xie, Tao Wu, Xuan Zeng, Shuang Chen, and Dian Zhou. "Learning from Highly Confident Samples for Automatic Knee Osteoarthritis Severity Assessment: Data from the Osteoarthritis Initiative." IEEE Journal of Biomedical and Health Informatics (2021).

Yifan Wang, , Xianan Wang, Tianning Gao, Le Du, and Wei Liu. "An Automatic Knee Osteoarthritis Diagnosis Method Based on Deep Learning: Data from the Osteoarthritis Initiative." Journal of Healthcare Engineering 2021 (2021). 